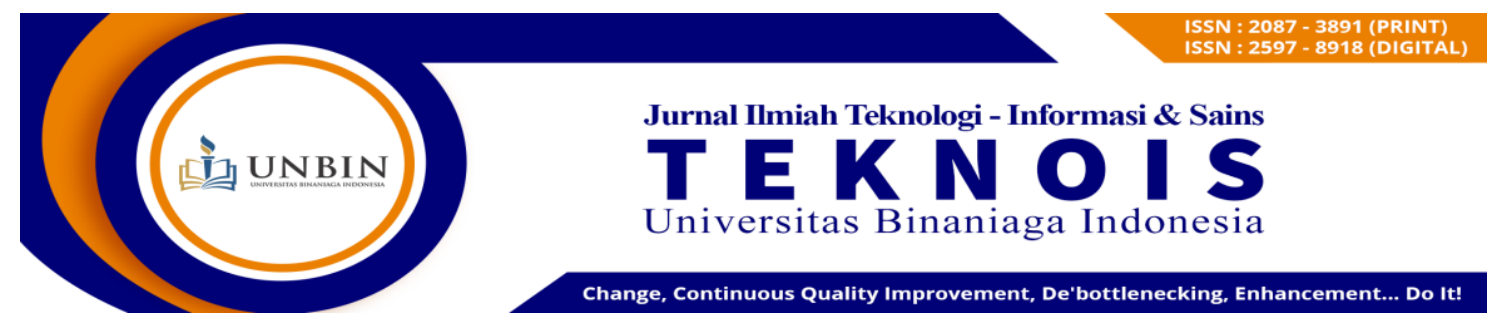

Article DOI : 10.36350/jbs.v10i2.94

Received: October; Accepted : October; Published : November

\title{
Penerapan COBIT 4.1 pada Domain Delivery and Support (DS) dan Monitoring and Evaluate (ME) untuk Mengukur Tingkat Kematangan Sistem Pelayanan
}

\author{
Alam Supriyatna ${ }^{1^{*}}$, Edi $^{2}$ \\ ${ }^{1}$ Sistem Informasi/STIKOM Binaniga \\ Email: alam@stikombinaniaga.ac.id \\ ${ }^{2}$ Sistem Informasi/STIKOM Binaniga \\ Email: edi_depok78@gmail.com
}

\begin{abstract}
ABSTRAK
Pada era sekarang ini teknologi informasi telah terbukti memegang peranan penting dalam menciptakan value yang menjadi keunggulan bersaing bagi perusahaan. Penerapan teknologi informasi dalam dunia bisnis bukan saja menjadi pertimbangan penting, melainkan sangat strategis. Departemen TI merupakan yang paling bertanggung jawab dalam pengelolaan teknologi informasi, baik dari segi pengelolaan sistem informasi, daur hidup sistem maupun pengembangan terhadap sistem dan seluruh sumber daya TI demi kebutuhan perusahaan. Untuk mendapatkan nilai bisnis dan untuk mengukur sejauh mana pengelolaan TI yang dilakukan departemen TI, maka perusahaan perlu metode untuk pengukuran tata kelola TI di perusahaan. COBIT menyediakan parameter untuk penilaian setinggi dan sebaik apa pengelolaan IT pada suatu organisasi dengan menggunakan maturity models yang bisa digunakan untuk penilaian kesadaran pengelolaan (management awareness) dan tingkat kematangan (maturity level). COBIT mempunyai model kematangan (maturity models) untuk mengontrol proses-proses IT dengan menggunakan metode penilaian (scoring) sehingga suatu organisasi dapat menilai proses-proses IT yang dimilikinya.
\end{abstract}

Keywords: Cobit; Maturity Level; Delivery and Support; Monitoring and Evaluate.

\section{A. PENDAHULUAN}

\section{Latar Belakang}

Di era globalisasi persaingan bisnis yang semakin ketat, telah membuat banyak perusahaan harus berusaha lebih keras agar dapat tetap bertahan di dalam dunia bisnis yang serba dinamis. Perusahaan secara berkesinambungan mengatur ulang strategi dan kinerja dalam menghadapi persaingan bisnis tersebut. Perkembangan teknologi saat ini telah berkembang sedemikian cepatnya. Hal ini dirasakan dengan ada banyaknya perusahaan yang meng-gunakan sistem aplikasi berbasis web sebagai alat atau media untuk memudahkan pelanggan dengan aplikasi ini perusahaan mendapatkan banyak keuntungan baik dari segi ekonomi maupun teknologi.

Teknologi informasi saat ini menjadi bagian yang tak terpisahkan dan terintegrasi dengan tujuan bisnis perusahaan. Bagaimana teknologi informasi diaplikasikan dalam suatu perusahaan akan mempengaruhi seberapa jauh perusahaan tersebut telah mencapai visi, misi dan tujuan steategisnya (Sarno, 2009). 
PT Telekomunikasi Selular (Telkomsel) yang bergerak di bidang jasa telekomunikasi selular yang berdiri sejak tahun 1995 dan Kepemilikan sahamnya 65\% oleh Telkom dan 35\% oleh Singtel terus mengalami perkembangan dengan bertambahnya network dan jumlah pelanggan yang tersebar diseluruh Indonesia dari sabang sampai marauke.

Dengan jumlah pelanggan yang terus bertambah dari waktu ke waktu, pelayanan terhadap pelanggan harus terus ditingkatkan untuk membuat mudah dan nyaman dalam melayani para pelanggan sehingga tumbuh loyalitas pelanggan terhadap produk telkomsel. Untuk melayani pelanggan PT.Telkomsel membuat pusat pelayanan yang tersebar dikota-kota diseluruh Indonesia dan juga menyediakan pelayanan dengan menggunakan teknologi informasi berbasis web semua ini diadakan untuk melayani pelanggan, bila terjadi masalah atau kendala terhadap produk Telkomsel dapat mendatangi pusat layanan atau mengunjungi website yang sudah disediakan oleh telkomsel bila terjadi suatu masalah pada SIM card.

PT.Telkomsel sudah membuat sistem berbasis web untuk mengikuti perkembangan teknologi informasi yang sangat pesat dalam melayani pelanggan dan penggunaannya pun sangat mudah sehingga para pelanggan tidak perlu datang kepusat pelayanan karena hampir semua permasalahan dapat diselesaikan secara online, tetapi pada kenyataannya masih banyaknya pelang-gan datang kepusat pelayanan Telkomsel khususnya dipusat pelayanan Garapri Bogor yang mana pelanggan Telkomsel wilayah bogor sebanyak 755.000 pelanggan, data kunjungan pelanggan wilayah bogor pada bulang September 2013 sebanyak 10207 dengan berbagai permasalahan. Dengan banyaknya pelanggan datang ke pusat layanan grapari Bogor maka perlu memastikan sejauh mana tingkat kematangan sistem pelayanan online PT.Telkomsel khususnya untuk wilayah bogor.

Salah satu model acuan dapat digunakan untuk mengetahui tingkat kematangan adalah model kematangan (maturity model) COBIT 4.1 (control objectives for information and related technology) adalah suatu panduan standar praktik manajemen teknologi informasi. Standar COBIT dikeluarkan oleh IT Governance Institute yang merupakan bagian dari ISACA (Information Systems Audit and Control Association) (ISACA, 2007). Dengan COBIT 4.1 pengguna Teknologi Informasi dapat memperoleh keyakinan atas kehandalan teknologi yang dipergunakan.

Dari penelitian ini diharapkan dapat diketahui sejauh mana peranan sistem informasi dapat merepresentasikan tujuan bisnis serta terukurnya tingkat kematangan sistem informasi pelayanan. Sehingga temuan-temuan dari pelaksanaan pengukuran menghasilkan rekomendasi yang dapat digunakan PT.Telkomsel sebagai referensi untuk meningkatkan peranan dan pengelolaan sistem informasi agar kedepannya dapat mendukung tujuan bisnis organisasi dengan lebih baik.

\section{Rumusan Masalah}

PT. Telkomsel dalam meningkatkan pelayanan terhadap pelanggan sudah menyediakan layanan berbasis Teknologi Informasi dan sangat diharapkan bisa mengoptimalisasi pelayanan terhadap pelanggan mengingat pelanggan Telkomsel sudah lebih dari 125 Juta, akan tetapi masih adanya pelanggan datang ke kantor pelayanan untuk permasalahan yang sudah dapat diselesaikan dengan pelayanan online seperti tagihan, membuka PUK yang terblokir dan yang lainnya. Dengan banyak pelanggan datangnya ke grapari Bogor sehingga membutuhkan customer service yang banyak pula untuk melayani pelanggan karena PT.Telkomsel mengutamakan kecepatan dan ketepatan dalam memberikan pelayanan terhadap pelanggan. Dengan banyaknya customer service maka biaya yang timbul untuk kegiatan melayani pelanggan juga akan bertambah selain itu ruangan dalam melayani pelanggan juga harus ditingkatkan untuk menjaga para pelanggan agar tetap nyaman, mengingat tempat pusat layanan grapari bogor tidak terlalu besar dan area parkir pun tidak terlalu luas sehingga bila pelanggan yang datang banyak maka kenyamanan dan pelayanan tidak maksimal. Data kunjungan pelanggan ke grapari Bogor bulan September 2013 adalah sebanyak 10207 pelanggan seperti tabel dibawah ini: 
Tabel 1. Data Identifikasi Kunjungan

\begin{tabular}{|c|c|c|}
\hline \multicolumn{3}{|c|}{ TELKOMSEL GRAPARI BOGOR } \\
\hline \multicolumn{3}{|c|}{$\begin{array}{l}\text { KUNJUNGAN PELANGGAN PADA BULAN } \\
\text { SEPTEMBER } 2013 \text { SEBANYAK } 10207\end{array}$} \\
\hline No & Permasalahan & Jumlah \\
\hline 1 & Kartu Rusak & 8201 \\
\hline 2 & Tagihan tidak sesuai & 35 \\
\hline 3 & Billing / Tagihan & 519 \\
\hline 4 & PIN terblock & 499 \\
\hline 5 & Setting gadget & 90 \\
\hline 6 & Open Internasional Roaming & 45 \\
\hline 7 & Open Blokir & 80 \\
\hline 8 & Pasang Baru & 75 \\
\hline 9 & Lain-lain & 663 \\
\hline & JUMLAH & 10207 \\
\hline
\end{tabular}

Berdasarkan Data yang diperoleh dari Team Support Call Center Bank Mega maka dapat diidentifikasi permasalahannya adalah sebagai berikut :

a. Belum Belum diketahui tingkat kebergunaan dari sistem aplikasi Media of Knowledge

b. Bagaimana penerapan Metode Usability Testing dalam mengukur tingkat kebergunaan sistem aplikasi Media of Knowledge?

\section{Tujuan}

Adapun tujuan dari penelitian ini adalah Untuk mengetahui tingkat pemetaan kematangan sistem pelayanan online PT. Telkomsel

\section{Tinjauan Pustaka}

a. IT Governance

IT Governance merupakan konsep yang berkembang dari sektor swasta, namun dengan berkembangnya penggunaan teknologi informasi (TI) oleh sektor publik (organisasiorganisasi pemerintahan), maka IT Governance juga diterapkan di sektor yang menuntut perbaikan pelayanan bagi masayarakat umum.

Penerapan teknologi informasi memiliki peranan penting dalam mencapai tujuan organisasi. Dengan pengelolaan TI yang baik diharapkan penerapan teknologi informasi dapat berjalan dengan optimal. Pengelolaan TI yang baik dilakukan dengan menilai kesesuaian antara penerapan TI dan proses bisnis organisasi. Ada beberapa definisi tata kelola TI menurut sumber yang berbeda.

b. COBIT 4.1

(Control objectives for information and related technologies) merupakan sekumpulan dokumentasi dan panduan yang mengarahkan pada IT governance yang dapat membantu auditor, manajemen, dan pengguna (user) untuk menjembatani pemisah antara resiko bisnis, kebutuhan kontrol, dan permasalahan-permasalahan teknis IT (Sasongko, 2009). COBIT dikembangkan oleh IT Governance Institute (ITGI), yang merupakan bagian dari Information Systems Audit and Control Association (ISACA). Pedoman COBIT 4.1 memungkinkan perusahaan untuk mengimplementasikan pengaturan TI secara efektif dan pada dasarnya dapat diterapkan di seluruh organisasi. Khususnya, komponen pedoman manajemen COBIT 4.1 yang berisi sebuah respon kerangka kerja untuk kebutuhan manajemen bagi pengukuran dan pengendalian TI dengan menyediakan alatalat untuk menilai dan mengukur kemampuan TI perusahaan untuk 34 proses TI COBIT 4.1 .

COBIT 4.1 membagi tahapan pengelolaan IT ke dalam 4 domain yaitu Planning \& Organisation, Acquisition \& Implementation, Delivery \& Support, dan Monitoring and Evaluation. COBIT 4.1 mengelompokkan semua aktivitas bisnis yang terjadi dalam organisasi menjadi 34 proses yang terbagi ke dalam empat buah domain proses tersebut, meliputi:

1) Planning \& Organisation. Domain ini menitikberatkan pada proses perencanaan dan penyelarasan strategi TI dengan strategi perusahaan, mencakup masalah strategi, taktik dan identifikasi cara terbaik IT untuk memberikan kontribusi maksimal terhadap pencapaian tujuan bisnis organisasi. 
2) Acquisition \& Implementation. Domain ini berkaitan dengan implementasi solusi IT dan integrasinya dalam proses bisnis organisasi, juga meliputi perubahan dan perawatan yang dibutuhkan sistem yang sedang berjalan untuk memastikan daur hidup sistem tersebut tetap terjaga.

3) Delivery \& Support. Domain ini mencakup proses pemenuhan layanan IT, keamanan sistem, kontinyuitas layanan, pelatihan dan pendidikan untuk pengguna, dan pemenuhan proses data yang sedang berjalan.

4) Monitoring and Evaluation. Domain ini berfokus pada masalah kendali-kendali yang diterapkan dalam organisasi, pemeriksaan intern dan ekstern dan jaminan independent dari proses pemeriksaan yang dilakukan.

\section{B. METODE}

Jenis penelitian ini adalah penelitian deskripstif, artinya mendeskripsikan system informasi yang digunakan, dalam hal ini untuk pemetaan tata kelola teknologi informasi pada Sistem pelayanan PT.Telkomsel

\section{Desain Penelitian}

Berisi tentang kerangka yang dijadikan pedoman dalam penyelesaian masalah yang terdiri dari tahapan-tahapan yang dilakukan dalam proses pemecahan masalah yang dimulai dari identifikasi masalah sampai pada tahap penarikan kesimpulan dan pengusulan saran-saran. desain penelitian yang digunakan dalam penelitian ini dijelaskan dalam gambar dibawah ini :

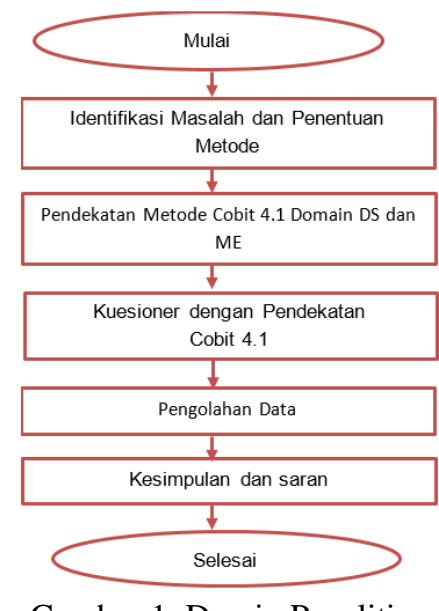

\section{Populasi dan Sample}

Gambar 1. Desain Penelitian

a. Populasi adalah jumlah keseluruhan dari satuan-satuan atau individu-individu yang karakteristiknya hendak diteliti. Populasi pada penelitian ini adalah seluruh jumlah tenaga IT dan yang berlatar belakang IT yang ada di PT. Telkomsel cabang bogor sebanyak 20 orang.

b. Sampel atau contoh adalah sebagian dari populasi yang karakteristiknya hendak diteliti. Sampel pada penelitian ini adalah seluruh populasi yang ada yaitu sebanyak 20 orang.

\section{Instrumen Penelitian}

Menurut Suharsimi Arikunto (2000:134), Instrumen pengumpulan data adalah alat bantu yang dipilih dan digunakan oleh peneliti dalam kegiatannya mengumpulkan agar kegiatan tersebut menjadi sistematis dan dipermudah olehnya.

Sebagai alat pengumpul data peneliti mencoba menyusun alat atau instrumen yang berupa pertanyaan kuesioner. Instrumen disusun berdasarkan penyebaran konsep teori, empiris dan operasional. yang terdiri dari :

Domain Delivery ans Support

a. DS1 - Menentukan dan mengelola tingkat layanan.

b. DS2 - Mengelola layanan dari pihak ketiga

c. DS3 - Mengelola performa dan kapasitas.

d. DS4 - Menjamin layanan yang berkelanjutan 

e. DS5 - Menjamin keamanan sistem.
f. DS7 - Mendidikan melatih pengguna
Domain Monitoring and Evaluation
a. ME1 - Mengawasi dan mengevaluasi performansi IT.
b. ME2 - Mengevaluasi dan mengawasi kontrol internal
c. ME3 - Menjamin kesesuaian dengan kebutuhan eksternal.
d. ME4 - Menyediakan IT Governance.

\section{Teknik Analisa Data}

Perhitungan indeks kematangan atribut setiap modul domain diperoleh dengan menjumlahkan total jawaban dari responden untuk setiap skala sikap pada setiap module DS dan ME dikalikan dengan bobot skala kemudian dibagi dengan jumlah responden, seperti berikut ini :

$$
\text { Indek Kematangan Atribut }=\frac{\sum(\text { Total Jawaban x Bobot })}{\text { Jumlah Responden }}
$$

Penilaian tingkat kematangan (maturity level) dilakukan dengan mempertimbangkan nilai indeks kematangan (maturity indeks) sesuai dengan jumlah dimensi dari domain yang digunakan

$$
\text { Indek Kematangan }=\frac{\sum \text { indek kematanganatribut }}{\text { Jumlah Indikator }}
$$

\section{HASIL DAN PEMBAHASAN}

\section{Identifikasi Business Goal}

Pada tahap ini akan di definisikan Business Goals yang berlaku di COBIT 4.1 yang diselaraskan dengan tujuan dari Sistem Pelayanan Online PT.Telkomsel. Adapun tujuan PT. Telkomsel adalah sebagai berikut :

a. Untuk mengukur tingkat kematangan Sistem Pelayanan Online PT.Telkomsel.

b. Untuk meningkatkan informasi Sistem Pelayanan Online kepada pelanggan.

c. Untuk memetakan kematangan Sistem Pelayanan Online PT.Telkomsel.

d. Miningkatkan kemampuan SDM pelayanan di bidang Sistem Pelayanan.

e. Mengembangkan sistem/aturan kemitraan dan kerjasama yang profesional secara internal dan eksternal sesuai dengan peraturan perundang-undangan yang berlaku.

Hasil dari pemetaan tujuan dari Sistem Pelayanan Online PT.Telkomsel bisa dilihat pada tabel berikut :

\begin{tabular}{|c|c|c|c|}
\hline NO & $\begin{array}{c}\text { Tujuan Sistem Pelayanan } \\
\text { Online PT. Telkomsel }\end{array}$ & Business Goals COBIT & $\begin{array}{l}\text { Perspektif Goals } \\
\text { COBIT }\end{array}$ \\
\hline 1 & $\begin{array}{l}\text { 1) Untuk mengukur tingkat } \\
\text { kematangan Sistem } \\
\text { Pelayanan Online } \\
\text { PT.Telkomsel. }\end{array}$ & $\begin{array}{l}\text { 7) Membuat terobosan } \\
\text { dalam menanggapi } \\
\text { perubahan kebutuhan } \\
\text { bisnis. }\end{array}$ & \multirow{3}{*}{$\begin{array}{l}\text { Perspektif } \\
\text { Pelanggan }\end{array}$} \\
\hline 2 & $\begin{array}{l}\text { 2) Untuk meningkatkan } \\
\text { informasi Sistem } \\
\text { Pelayanan Online kepada } \\
\text { pelanggan. }\end{array}$ & $\begin{array}{l}\text { 4) Meningkatkan orientasi } \\
\text { kepada pelanggan dan } \\
\text { pelayan. }\end{array}$ & \\
\hline 3 & $\begin{array}{l}\text { 3) Untuk memetakan } \\
\text { kematangan Sistem } \\
\text { Pelayanan Online } \\
\text { PT.Telkomsel. }\end{array}$ & $\begin{array}{l}\text { 6) Membangun } \\
\text { kesinambungan dan } \\
\text { ketersediaan layanan }\end{array}$ & \\
\hline 4 & $\begin{array}{l}\text { 4) Miningkatkan kemampuan } \\
\text { SDM pelayanan di bidang } \\
\text { Sistem Pelayanan. }\end{array}$ & $\begin{array}{l}\text { 17) Mendapatkan dan } \\
\text { mempertahankan } \\
\text { orang-orang terampil } \\
\text { dan termotivasi }\end{array}$ & $\begin{array}{l}\text { Perspektif } \\
\text { Pembelanjaan dan } \\
\text { Peningkatan }\end{array}$ \\
\hline 5 & $\begin{array}{l}\text { 5) } \\
\text { sistemgembangkan } \\
\text { dan kerjasama yang } \\
\text { profesional secara internal }\end{array}$ & $\begin{array}{l}\text { 12) Mematuhi hukum } \\
\text { ekternal, regulasi dan } \\
\text { kontrak }\end{array}$ & $\begin{array}{l}\text { Perspektif } \\
\text { Internal }\end{array}$ \\
\hline
\end{tabular}

Tabel 2. Pemetaan Business Goals

(C2020 Teknois : Jurnal Ilmiah Teknologi Informasi dan Sains. Copyrights All rights reserved 
Volume 10 Number 2 November 2020 Page. 80-88

Journal Homepage : http://teknois.stikombinaniaga.ac.id/index.php/JBS

DOI Link : http://doi.org/10.36350/jbs.v10i2

\begin{tabular}{|l|l|l|l|}
\hline & $\begin{array}{l}\text { dan eksternal sesuai } \\
\text { dengan peraturan } \\
\text { perundang-undangan yang } \\
\text { berlaku. }\end{array}$ & $\begin{array}{c}\text { 13) Mematuhi kebijakan } \\
\text { internal }\end{array}$ & \\
\hline
\end{tabular}

\section{Identifikasi IT Goal}

Setelah mengidentifikasi Business Goals langkah selanjutnya adalah mengidentifikasi IT goals yang sesuai dengan studi kasus. COBIT sendiri sudah memetakan Business Goals dengan IT Goals, dan dari pemetaan itu dapat terlihat IT Goals apa saja yang nantinya akan menunjang Business Goals organisasi berdasarkan busisness COBIT.

\section{Identifikasi IT Process}

Tahapan selanjutnya adalah penetapan IT proses yang sesuai dengan IT goals dan nantinya harus disesuaikan dengan studi kasus. Adapun IT process yang sesuai dengan IT goals yang berlaku untuk studi kasus ini adalah sebagai berikut :

Tabel 3. IT Proses Domain Delivery and Support \& Monitor and Evaluate

\begin{tabular}{|c|c|}
\hline IT Process & IT Domain \\
\hline $\begin{array}{c}\text { Delivery And Support } 1 \\
\text { (Menentukan dan mengelola tingkat layanan) }\end{array}$ & \multirow{6}{*}{ Delivery And Support } \\
\hline $\begin{array}{c}\text { Delivery And Support } 2 \\
\text { (Mengelola layanan dari pihak ketiga) }\end{array}$ & \\
\hline $\begin{array}{c}\text { Delivery And Support } 3 \\
\text { (Mengelola performa dan kapasitas) }\end{array}$ & \\
\hline $\begin{array}{c}\text { Delivery And Support } 4 \\
\text { (Menjamin layanan yang berkelanjutan) }\end{array}$ & \\
\hline $\begin{array}{l}\text { Delivery And Support } 5 \\
\text { (Menjamin keamanan sistem) }\end{array}$ & \\
\hline $\begin{array}{c}\text { Delivery And Support } 7 \\
\text { (Mendidikan melatih pengguna) }\end{array}$ & \\
\hline $\begin{array}{c}\text { Monitor and Evaluate } 1 \\
\text { (Mengawasi dan mengevaluasi performansi IT) }\end{array}$ & \multirow{4}{*}{ Monitor and Evaluate } \\
\hline $\begin{array}{c}\text { Monitor and Evaluate } 2 \\
\text { (Mengevaluasi dan mengawasi kontrol internal) }\end{array}$ & \\
\hline $\begin{array}{c}\text { Monitor and Evaluate } 3 \\
\text { (Menjamin kesesuaian dengan kebutuhan eksternal) }\end{array}$ & \\
\hline $\begin{array}{c}\text { Monitor and Evaluate } 4 \\
\text { (Menyediakan IT Governance) }\end{array}$ & \\
\hline
\end{tabular}

\section{Identifikasi Control Process}

Berdasarkan identifikasi IT Process, maka proses-proses yang diidentifikasi berikut adalah mencakup proses TI yang berdapat pada domain delivery and support berjumlah 6 proses dan monitor and evaluate berjumlah 4 proses yang semuanya berjumlah 10 proses TI.

Tabel 4. Keterangan setiap pernyataan kuisioner :

\begin{tabular}{|c|l|c|}
\hline No & \multicolumn{1}{|c|}{ Pernyataan } & Skor \\
\hline 1 & Sangat Setujut (SS) & 5 \\
\hline 2 & Setuju (S) & 4 \\
\hline 3 & Netral (N) & 3 \\
\hline 4 & Tidak Setuju (TS) & 1 \\
\hline 5 & Sangat Tidak Setuju (STS) \\
\hline
\end{tabular}


Volume 10 Number 2 November 2020 Page. 80-88

Journal Homepage : http://teknois.stikombinaniaga.ac.id/index.php/JBS

DOI Link : http://doi.org/10.36350/jbs.v10i2

\section{Hasil Pengukuran Tingkat Kematangan}

Dari proses pengukuran yang telah dilakukan, didapatkan hasil pengukuran tingkat kematangan pelayanan online PT.Telkomsel berbasis pada tingkat kematangan COBIT 4.1. Hasil tersebut dapat dilihat pada tabel dibawah ini

Tebel 5. Perhitungan tingkat kematangan domain DS

\begin{tabular}{|c|c|c|}
\hline Control Process COBIT & $\begin{array}{c}\text { Maturity } \\
\text { Level }\end{array}$ & Kriteria Level Kematangan \\
\hline $\begin{array}{c}\text { Delivery And Support 1 } \\
\text { (Menentukan dan mengelola tingkat } \\
\text { layanan) }\end{array}$ & $\mathbf{3 . 9 6}$ & Managed And Measureable \\
\hline $\begin{array}{c}\text { Delivery And Support 2 } \\
\text { (Mengelola layanan dari pihak ketiga) }\end{array}$ & $\mathbf{3 . 7 8}$ & Managed And Measureable \\
\hline $\begin{array}{c}\text { Delivery And Support 3 } \\
\text { (Mengelola performa dan kapasitas) }\end{array}$ & $\mathbf{3 . 9 2}$ & Managed And Measureable \\
\hline $\begin{array}{c}\text { Delivery And Support 4 } \\
\text { (Menjamin layanan yang } \\
\text { berkelanjutan) }\end{array}$ & $\mathbf{3 . 9 2}$ & Managed And Measureable \\
\hline $\begin{array}{c}\text { Delivery And Support 5 } \\
\text { (Menjamin keamanan sistem) }\end{array}$ & $\mathbf{3 . 9 9}$ & Managed And Measureable \\
\hline $\begin{array}{c}\text { Delivery And Support 7 } \\
\text { (Mendidik dan melatih pengguna) }\end{array}$ & $\mathbf{4 . 1 8}$ & Managed And Measureable \\
\hline
\end{tabular}

Hasil perhitungan tingkat kematangan pada tabel 21 secara keseluruhan menunjukkan nilai 3.95 (Manage and Measurable). Nilai tersebut diperoleh dari total nilai 6 kendali proses COBIT 4.1 dibagi 6 kendali proses. Berdasarkan Level Maturity Model maka rata-rata nilai yang diperoleh dari 6 kendali proses COBIT 4.13.95 adalah termasuk ke dalam level 4 yaitu Manage and Measurable. Kondisi yang dapat digambarkan dari level ini adalah organisasi membuat suatu matrik untuk suatu produk, proses dan pengukuran hasil. Sistem pelayanan online mempunyai kontrol terhadap produk dan proses untuk mengurangi variasi kinerja proses sehingga terdapat batasan yang dapat diterima.

Tabel 6. Perhitungan tingkat kematangan domain ME

\begin{tabular}{|c|c|c|}
\hline Control Process COBIT & $\begin{array}{c}\text { Maturity } \\
\text { Level }\end{array}$ & Kriteria Level Kematangan \\
\hline $\begin{array}{c}\text { Monitoring and Evaluation 1 } \\
\text { (Mengawasi dan mengevaluasi } \\
\text { performansi IT) }\end{array}$ & $\mathbf{3 . 9 1}$ & Managed And Measureable \\
\hline $\begin{array}{c}\text { Monitoring and Evaluation 2 } \\
\text { (Mengevaluasi dan mengawasi kontrol } \\
\text { internal) }\end{array}$ & $\mathbf{3 . 9 5}$ & Managed And Measureable \\
\hline
\end{tabular}


Volume 10 Number 2 November 2020 Page. 80-88

Journal Homepage : http://teknois.stikombinaniaga.ac.id/index.php/JBS

DOI Link : http://doi.org/10.36350/jbs.v10i2

\begin{tabular}{|c|c|c|}
\hline $\begin{array}{c}\text { Monitoring and Evaluation 3 } \\
\text { (Menjamin kesesuaian dengan } \\
\text { kebutuhan eksternal) }\end{array}$ & $\mathbf{4 . 1 6}$ & Managed And Measureable \\
\hline $\begin{array}{c}\text { Monitoring and Evaluation 4 } \\
\text { (Menyediakan IT Governance) }\end{array}$ & $\mathbf{3 . 9 4}$ & Managed And Measureable \\
\hline Total & $\mathbf{3 . 9 9}$ & Managed And Measureable \\
\hline
\end{tabular}

Hasil perhitungan tingkat kematangan pada tabel 22 secara keseluruhan menunjukkan nilai 3.99 (Manage and Measurable). Nilai tersebut diperoleh dari total nilai 4 kendali proses COBIT 4.1 dibagi 4 kendali proses. Berdasarkan Level Maturity Model maka rata-rata nilai yang diperoleh dari 4 kendali proses COBIT 4.1 3.99 adalah termasuk ke dalam level 4 yaitu Manage and Measurable. Kondisi yang dapat digambarkan dari level ini adalah organisasi membuat suatu tata kelola IT, sehingga dengan demikian tata kelola IT berjalan dengan sesuai prosedur yang telah diterapkan. Resiko perpindahan teknologi produk, proses pembuatan, dan pasar harus diketahui dan diatur secara hati-hati. Proses pengembangan dapat ditentukan karena proses diukur dan dijalankan dengan limit yang dapat diukur.

\section{Posisi Perusahaan Terhadap Standar Internasional Maturity Level}

Penilaian maturity level yang dikemukakan oleh Pederiva (2003). Bahwa standar yang ditetapkan secara internasional adalah 2.5 dari total keseluruhan 5 poin. Dengan demikian, posisi Sistem pelayanan online PT.Telkomsel dapat dikatakan berada di atas standar internasional dengan angka untuk domain DS 3.95 dan untuk domain ME 3.99. Gambar 2 menunjukan posisi perusahaan terhadap standar internasional.

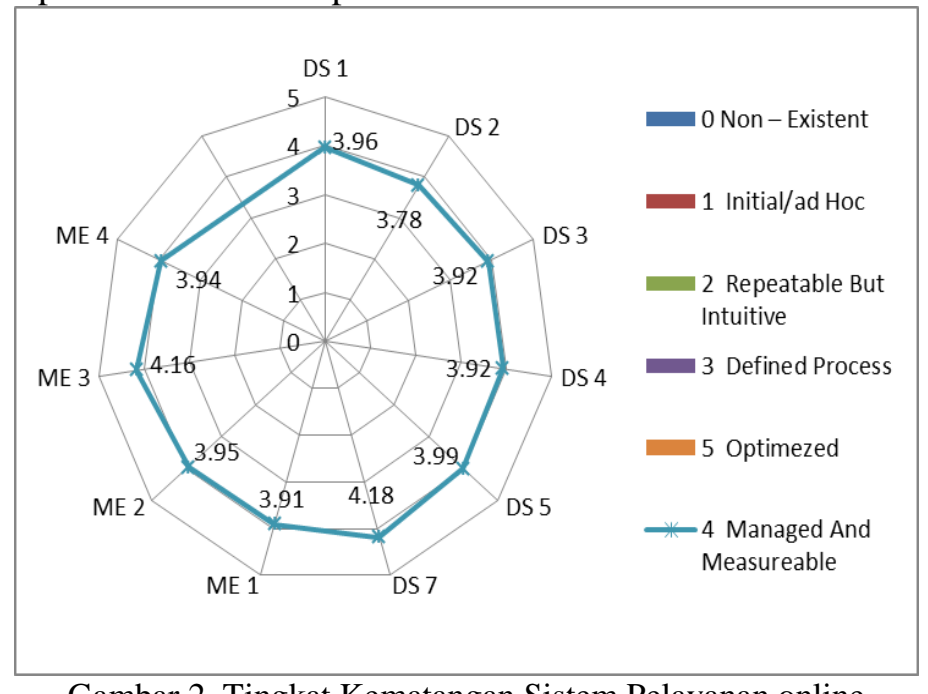

Gambar 2. Tingkat Kematangan Sistem Pelayanan online

\section{KESIMPULAN}

Berdasarkan hasil penelitian yang telah dilakukan terhadap tingkat kematangan sistem aplikasi pelayanan online PT. Telkomsel dengan menggunakan kerangka kerja COBIT pada domain Delivery And Support, PT. Telkomsel mendapat skor 3.95. dan pada domain Monitoring and Evaluation, PT. Telkomsel mendapat skor 3.99.

Dari hasil pembahasan dan analisis data yang telah dilakukan maka dapat disimpulkan bahwa :

1. Pengukuran tingkat kematangan sistem aplikasi pelayanan online PT. Telkomsel penting dilakukan agar kesesuaian target pekerjaan yang dicapai dengan perencanaan dan tugas dapat berjalan dengan baik. Dengan mengacu pada Framework COBIT 4.1 dan menggunakan kendali proses yang ada di dalam COBIT, tingkat kematangan sistem aplikasi pelayanan online telah diketahui berada pada level 4 (Manage and Meausurable), kondisi tersebut 
Volume 10 Number 2 November 2020 Page. 80-88

Journal Homepage : http://teknois.stikombinaniaga.ac.id/index.php/JBS

DOI Link : http://doi.org/10.36350/jbs.v10i2

menyatakan bahwa sistem apliksi pelayanan online sudah memiliki kontrol yang baik dalam pelaksanaan Teknologi Informasi.

2. Penerapan sistem aplikasi pelayanan online PT. Telkomsel masih perlu dievaluasi meskipun berada pada level 4 terutama pada proses mengelola layanan dari pihak ketiga. Kondisi tersebut dapat dilihat pada tingkat kematangan pada kendali proses DS2 yang mendapatkan nilai terendah yaitu 3.78 .

\section{E. DAFTAR PUSTAKA}

[1] Aditya Warman (2012) Pengukuran ting-kat kematangan penyelarasan stra-tegi teknologi informasi terhadap strategi bisnis analisi menggunakan framework COBIT 4.1

[2] Herianto dan Achmad Nizar Hidayanto (2010) Identifikasi portofolio ,strategic sourcing dan pengukuran keter-sediaan layanan TI pada PT.PLN (Persero) wilayah Sumatra selatan, jambi dan Bengkulu PT. PLN Wilayah Sumsel, Jambi dan Bengkulu.

[3] Irmayansyah, Mrs, and Agustina R. Putri. "Pengukuran Tingkat Kematangan Simaster Menggunakan Cobit 4.1 di SMA Plus Bbs Bogor." Teknois, vol. 7, no. 1, May. 2017, pp. 47-58, doi:10.36350/jbs.v7i1.33.

[4] IT Governance Institute (2003), it Gover-nance Implement Guide: "How do I use COBIT to Implement IT Governance?", IT Governance, Illionois.

[5] ITGI (Information Technology Gover-nance Institute), (2007), “ Control Objectives For Information And related Technology COBIT 4.1 “

[6] IT Governance Institute (2008a), "IT Governance and Process Maturity", IT Governance Institute.

[7] O’ Brien dan George (2006) Mana-gement Information System. Mc Graw Hill, USA

[8] Pederiva, A. (2003). The COBIT ${ }^{\circledR}$ maturity model in a vendor evaluation case. Information Systems Control Journal

[9] Sarno, R., (2009) Strategi Sukses Bisnis dengan Teknologi Informasi Bebasis Balanced Scorecard \& COBIT, ITS Press, Surabaya.

[10] Suharsimi Arikunto.2000. Manajemen Penelitian. Jakarta: Rineke Cipta.

[11] Sugeng Winardi (2012) Universitas respati Yogyakarta fakultas sains dan teknologi tentang Penerapan kerangka kerja COBIT 4.1 untuk menilai pengelolaan teknologi informasi dan tingkat pelayanan 